\title{
Construction of Innovation and Entrepreneurship Training System for Network Information Security Talents
}

\author{
Bin Han *, Zhi Qin, Ding Chen and Xiangmei Li \\ Chengdu University of Information Technology, Chengdu, Sichuan, 610225 \\ *Corresponding author.Email: hanbin@cuit.edu.cn
}

\begin{abstract}
This paper studies how to create a training system of innovation and entrepreneurship ability of Cyberspace Security Specialty by researching the current situation of college education, stimulate students' innovative thinking and entrepreneurial consciousness, and comprehensively improve students' innovative practice ability and entrepreneurial level.
\end{abstract}

Keywords: Innovation, Entrepreneurship and talent training.

\section{INTRODUCTION}

With the rapid development of information technology and the arrival of the era of big data, China has put forward new requirements for the innovation and entrepreneurship ability of talents. To create a high-level application-oriented university and deepen the reform of innovation and entrepreneurship education in Colleges and universities is an urgent need for the state to implement the innovation driven development strategy and promote the quality and efficiency of the economy. It is also an important measure to promote the comprehensive reform of higher education and promote the employment of college graduates with higher quality.

Chengdu University of information engineering is a Provincial General Undergraduate University jointly established by Sichuan Province and China Meteorological Administration and mainly developed by Sichuan Province. In 2003, the University was granted the right to confer master's degree; in 2007, it was awarded the "excellent" undergraduate teaching level evaluation of the Ministry of education; in 2010, the University was selected into the first batch of 61 pilot colleges of "excellent engineer education and training program"; in 2013, it was selected as the western infrastructure capacity construction engineering university. In 2017, our school's cyberspace security discipline was listed in the first batch of "double first-class" construction disciplines in Sichuan Province.
In 2018, it was approved as a provincial application demonstration specialty, and in the same year, it was approved as a master's degree authorization point of Cyberspace Security discipline. It has a complete talent training system from undergraduate to master.

This paper will build a perfect talent training and practical teaching system, optimize teachers and practical teaching resources, cultivate various types of network and information security talents in line with the society, promote the healthy development of network security majors, and explore a new method and way for the "entrepreneurship and innovation" education in Colleges and universities.

\section{CONSTRUCTION OF INNOVATION AND ENTREPRENEURSHIP TRAINING SYSTEM}

\subsection{Optimize the Curriculum System of Innovation and Entrepreneurship Education}

Guided by the concept of innovation and entrepreneurship education, optimize the training scheme of cyberspace security professionals, integrate the innovation and entrepreneurship ideas and contents into the professional teaching main courses and practice learning system, and construct the innovation and entrepreneurship education curriculum system composed of "general education + professional 
education + Innovation Education + innovation practice + entrepreneurship training", and put innovation and entrepreneurship education throughout the whole process of talent training Step by step to realize the formation of innovation consciousness, the reserve of innovative knowledge and the improvement of innovation ability.

(1) In the design of professional training plan, it is necessary to fully consider the proportion of required courses and elective courses of innovation and entrepreneurship as well as the disadvantageous relationship with professional courses, and develop and open professional innovation and entrepreneurship courses that closely meet the industrial development, regional needs and job requirements.

(2) Introduce enterprise tutor and design enterprise tutor courses in related industries. Through the education platform of local enterprises, there will be no gap between enterprises and local enterprises.

(3) The system of progressive curriculum in junior and senior grades. General education courses are mainly offered in lower grades, while specialized courses, simulation training courses and actual combat training courses are offered in higher grades. The whole process of education is fully spread through the progressive curriculum system.

(4) In the practice course, with the help of "school enterprise" and "school local" cooperation platform, students are guided to participate in practical engineering project practice, and students' innovative thinking, professional confidence and employment strength are stimulated.

\subsection{Building a Whole Process Innovation and Entrepreneurship Training System Based on "Competition + Project"}

(1) Open the laboratory, provide software and hardware platform for students to carry out innovation and entrepreneurship practice, and increase the opportunity of students' innovation and entrepreneurship practice. The open laboratory is equipped with special instructors to provide guidance for students' innovation and entrepreneurship activities.

(2) We should integrate the teaching resources in the school, unite the students of the college and other majors to form an interdisciplinary innovation and entrepreneurship team, allocate special venues for students to carry out innovation and entrepreneurship activities, and provide team platform and site platform for students' innovation and entrepreneurship. At the same time, the tutor group of innovation and entrepreneurship competition was established to actively participate in the design innovation and entrepreneurship competition, and students were encouraged to practice.

(3) Set up innovation and entrepreneurship projects to provide financial support for students to carry out innovation and entrepreneurship training. Actively carry out innovation and entrepreneurship training and simulated entrepreneurship practice, organize the excellent innovation and entrepreneurship achievements of students into a volume, carry out centralized promotion and publicity, mobilize the entrepreneurial enthusiasm of students, and form the campus culture of innovation and entrepreneurship.

Innovation and entrepreneurship discipline competition requires students to have better technological literacy and innovative spirit. Actively organize students of all grades to participate in competition and Internet plus safety competitions at all levels, and guide students to report or participate in science and technology innovation projects at all levels or open experimental projects according to their own interests, so as to fully train students' innovation. Thinking and developing students' creativity. In recent years, the college students have successfully declared over 100 innovative and entrepreneurial projects at the national, provincial and university levels, and have won many achievements in various domestic and foreign innovation and entrepreneurship competitions including "Challenge Cup" and "Internet plus".

\subsection{Building an Integrated Innovation and Entrepreneurship Practice Platform}

Based on the idea of "normalization and integration of innovation", an integrated innovation and entrepreneurship practice platform is built by relying on various kinds of science and technology innovation service platforms, experimental teaching demonstration centers, off campus practical education bases for college students, and entrepreneurship incubation bases for college students. Through system integration, resource sharing and information exchange, the platform becomes a practical platform for resource sharing, scientific management and deep opening, and a practical platform for the transformation of innovation achievements into entrepreneurial practice, providing strong resource guarantee for students to carry out discipline competitions and scientific and technological innovation activities.

The innovation and entrepreneurship practice platform is centered on the team set up by students freely. It forms a practical teaching mode of tutor driving students, project driving team, cooperation driving innovation and experiment promoting creativity, project promoting innovation, and practice promoting creation. It realizes the development of students' ability 
and personality in the cultivation of innovative thinking, innovative ability and entrepreneurial consciousness.

(1) We should make full use of the network security experiment center, engineering practice center and other practical training resources to build innovation and entrepreneurship training platform; we should build the innovation and entrepreneurship collaborative education platform through the technology center or research center jointly built by the University and the University; In the aspect of setting up business incubator, it can provide students with business incubator and technology incubator as soon as possible.

(2)Create the atmosphere of innovation and Entrepreneurship: establish students' innovation and entrepreneurship Association. Under the guidance of teachers, students can learn and explore the theoretical knowledge of innovation and entrepreneurship into their practical ability through the innovation practice activities of innovation and entrepreneurship association according to their own interests and specialties. The "clover" and "Doug" groups of two information security professional student associations established by the college, bring the old to the new, and give full play to the creativity and initiative of students. The college organizes students to participate in provincial and national information security competitions and college students' innovation and entrepreneurship projects with mass organizations as the core. Those who take part in learning through competitions and promote learning through competitions have won 35 provincial and national awards in the past three years, which have attracted the attention of brother colleges and enterprises and institutions in the field of information security.

\subsection{Strengthen the Construction of Innovation and Entrepreneurship Teaching Staff}

To strengthen the education of innovation and entrepreneurship, it is necessary to cultivate a team of teachers with innovative consciousness and practical ability. Through the way of "combination of introduction and training, combination of full-time and part-time, classified guidance", the innovation tutor Library of college students is established, which is composed of experts and professors, enterprise technical personnel, successful entrepreneurs and outstanding entrepreneurial students, forming a comprehensive guidance.

The training mechanism of in-service teachers' engineering practice ability is constructed. Teachers are guided to participate in the actual engineering projects of enterprises through the platform of industry university research cooperation, and the engineering ability and innovation and entrepreneurship ability of teachers are cultivated through regular off campus practice bases.
(1)Invite high-quality innovation and entrepreneurship experts and scholars to proofread teachers regularly for training, so that teachers have a macro understanding and understanding of innovation and entrepreneurship education, and change teachers' traditional thinking habits and teaching mode.

(2) Employing well-known experts and professors and engineers with rich engineering experience in enterprises as part-time teachers to teach students can not only improve the teaching effect, but also play the role of demonstration teaching.

(3) Select professional backbone teachers to exercise in the specific projects of the cooperative enterprise in holidays or spare time, deeply understand the enterprise's management philosophy, increase practical experience, and cultivate the ability of innovation and entrepreneurship. Teachers are encouraged to take part-time jobs in enterprises, learn advanced technologies, introduce advanced technologies and concepts into the teaching process, and cultivate students' innovative awareness and ability to solve practical problems.

(4) Teachers are encouraged to constantly update their knowledge structure in combination with their own professional and industrial development. Through various ways such as online training, offline learning and data access, teachers are encouraged to continuously cultivate their own awareness of innovation and entrepreneurship and improve their quality of innovation and entrepreneurship.

\section{CONCLUSION}

The network engineering specialty of the college has been approved to be the pilot specialty of the national excellent engineer training plan, and the information security major has been approved to be the pilot specialty of the Sichuan excellent engineer training plan. These two majors have become the double first-class majors in Sichuan Province, and are preparing for the application of the national first-class specialty.

Since the promotion of innovation and entrepreneurship education and the development of school enterprise cooperation, the college students majoring in network engineering and information security have significantly increased their interest in learning professional knowledge, and their learning motivation is more abundant. In recent 5 years, there are several student project teams to declare a number of innovative and entrepreneurial projects at the national, provincial and college levels, and guide students to participate in many college students' innovation and entrepreneurship competitions including Internet plus. In 2015-2020, they won the provincial Silver Award and bronze medal. And some students succeed in starting a 
business after graduation, which has received good social benefits.

I hope that through this study, we can provide some reference and reference for the innovation and Entrepreneurship Talent Training and practical education of colleges and universities in China, and cultivate more excellent application-oriented talents.

\section{REFERENCES}

[1] Liu Ming, Wang Yi, research and practice of innovation and entrepreneurship training system for local undergraduate students [J], JOURNAL OF INNER MONGOLIA AGRICULTURAL UNIVERSITY (SOCIAL SCIENCE EDITION). 2018 (3): 74-78
[2] Zhao Jianhua, Liu Ning, exploration of innovation and entrepreneurship education practice system of computer specialty in Application-oriented Universities [J], microcomputer application.2018 (12): $30-32$

[3] Zhan Songqing, on the cultivation of innovative and entrepreneurial talents of new engineering in local universities [J], Journal of Minnan Normal University (PHILOSOPHY AND SOCIAL SCIENCES EDITION). 2020 (2): 96-101

[4] Ge Huilin, Zhou Qingwen, exploration and practice of innovation and entrepreneurship education in Colleges and Universities under the background of new engineering $[\mathrm{J}]$, Journal of higher education. 2020 (19): 51-57 